\title{
Interactions of the Platelets in Paroxysmal Nocturnal Hemoglobinuria with Complement

\author{
Relationship to Defects in the Regulation of Complement and to Platelet Survival In Vivo
}

\author{
Dana V. Devine, * Robert S. Siegel, ${ }^{\star}$ and Wendell F. Rosse** \\ *Department of Microbiology and Immunology and ${ }^{\ddagger}$ Department of Medicine, \\ Duke University Medical Center, Durham, North Carolina 27710
}

\begin{abstract}
The blood cells of patients with paroxysmal nocturnal hemoglobinuria (PNH) have abnormal interactions with complement. The activity of the alternative pathway $\mathrm{C} 3$ convertase on the platelets of 9 out of 19 patients with PNH was elevated. 10 patients had $\mathrm{C} 3$ convertase activity within the normal range even though $80-95 \%$ of their platelets lacked the complement regulatory protein decay accelerating factor (DAF) that is absent from the affected blood cells in PNH. PNH and normal platelets released factor $\mathrm{H}$ when $\mathrm{C} 3$ was bound to their surfaces. This may account for the apparent regulation of $\mathrm{C} 3$ convertase activity on platelets that lack DAF. The abnormal uptake of the membrane attack complex of complement by PNH III erythrocytes was not seen in PNH platelets. ${ }^{111}$ Indium-labeled platelet survival times were normal in five of eight patients, which suggests that the lack of the membrane attack complex defect results in normal platelet survival in PNH.
\end{abstract}

\section{Introduction}

Paroxysmal nocturnal hemoglobinuria $(\mathrm{PNH})^{1}$ is a hematopoietic stem cell disorder characterized by an increased sensitivity of the blood cells to complement-mediated lysis, hematocytopenia, and a propensity toward intravascular coagulation (1-3). The PNH erythrocyte may be abnormal in one or two of its interactions with complement. PNH II erythrocytes show an inability to regulate the $\mathrm{C} 3$ convertases formed on the cell surface $(4,5)$. As a result, these cells are three to five times more sensitive to complement than normal erythrocytes (6). PNH III erythrocytes have increased sensitivity to the terminal components of complement, the membrane attack complex (7). This defect may actually be twofold. PNH III erythrocytes are unable to bear as many membrane attack complexes on their surface as a

Dr. Siegel is now Assistant Professor of Medicine, Division of Hematology/Oncology at The George Washington University Medical Center, Washington, D.C. Address reprint requests to Dr. Devine, Box 3934, Duke University Medical Center, Durham, NC 27710. 1986.

Received for publication 19 May 1986 and in revised form 11 August

1. Abbreviations used in this paper: CLS, complement lysis sensitivity; CoVF, cobra venom factor; CoVFBb, complexes formed from CoVF and activated factor B; DAF, decay accelerating factor, FITC, fluorescein isothiocyanate; GVB, veronal-buffered saline containing $0.1 \%$ gelatin; PFA, paraformaldehyde; PNH, paroxysmal nocturnal hemoglobinuria.

J. Clin. Invest.

(c) The American Society for Clinical Investigation, Inc.

0021-9738/87/01/0131/07 \$1.00

Volume 79, January 1987, 131-137 normal red cell before a lytic pore is created (8). In addition, when membrane attack complexes are generated in serum, they readily bind to the surface of PNH III cells but not to the surface of normal cells $(9,10)$. Having both the $C 3$ convertase and terminal complex defects makes the PNH III red cell 15-25 times more susceptible to complement lysis than normal red cells (6).

Recently, the PNH erythrocyte $(11,12)$ as well as the PNH platelet, monocyte, and granulocytes (13), have been found to lack decay accelerating factor (DAF), a protein that regulates both the classical and alternative pathway $\mathrm{C} 3$ convertases on the surface of erythrocytes (14-16). The deficiency of this molecule seems to be responsible for the defect in the regulation of the activation of C3 shared by PNH II and PNH III cells. However, although PNH II red cells reconstituted with purified DAF lose their increased susceptibility to complement, PNH III cells remain sensitive to the membrane attack complex (17). The molecular basis for the terminal complex defect of PNH III erythrocytes remains to be elucidated.

The platelets of patients with PNH are also abnormally sensitive to the lytic action of complement when complement is activated by platelet-specific antibody (18). The in vivo significance of this observation is not clear. Although some patients with PNH have a reduced platelet count, generally in the context of pancytopenia, many have platelet counts well within normal range. It is not known whether PNH platelets also have two defects in complement regulation similar to the erythrocyte. Using antibody-binding assays, we have measured DAF in the platelets of 20 patients with PNH. We have determined the relative percentage of abnormal platelets in the total platelet population in these patients and compared this with the relative percentage of abnormal erythrocytes. We have measured the activity of stabilized alternative pathway $\mathrm{C} 3$ convertases formed on the surface of PNH platelets as well as the ability of the PNH platelet to take up membrane attack complexes under the conditions of reactive lysis. To assess the impact of defects in complement regulation on the survival of platelets, "11 In-labeled platelet survival studies have been performed on eight patients with PNH.

\section{Methods}

Buffers, complement components, and antisera. All experiments were carried out in either veronal-buffered saline $(5.0 \mathrm{mM}$ sodium barbital, $0.15 \mathrm{M} \mathrm{NaCl}$, and $0.1 \%$ gelatin [pH 7.5]) containing $0.015 \mathrm{M}$ EDTA (GVB-EDTA) or veronal-buffered saline containing $0.15 \mathrm{mM}$ calcium chloride and $0.5 \mathrm{mM}$ magnesium chloride $\left(\mathrm{GVB}^{++}\right)$or $2.5 \mathrm{mM}$ magnesium alone $\left(\mathrm{GVB}^{+}\right)$. Cobra venom factor (CoVF; reference 19), C3 (20), factor B (4), factor D (21), C3 nephritic factor (22), and DAF (15) were purified using previously described methods. Purified thrombin was the gift of Dr. John W. Fenton, III (New York Department of Health, Albany, NY). Antiserum to human erythrocyte DAF was raised in rabbits in this laboratory. This antiserum was monospecific on platelets as de- 
termined by Western blot analysis. Goat anti-human factor $\mathrm{H}$ and rabbit anti-human $\mathrm{C} 3 \mathrm{c}$ was purchased from Calbiochem-Behring Corp., (LaJolla, CA). Monoclonal anti-human C3c was the gift of Dr. J. Donald Capra (University of Texas, Dallas, TX) and Dr. Gordon Ross (University of North Carolina, Chapel Hill, NC). Monoclonal anti-poly C9, which recognizes a neoantigen expressed by polymerized C9 or MC5b-9 (23), was the gift of Dr. Ronald J. Falk (University of North Carolina at Chapel Hill). Fluorescein isothiocyanate (FITC)-labeled affinity-purified $F\left(a^{\prime}\right)_{2}$ goat anti-rabbit IgG was prepared by Jackson Immunoresearch Laboratories (Avondale, PA) and peroxidase-conjugated rabbit anti-goat was purchased from BioRad Laboratories, (Richmond, CA). Staphylococcal Protein A was obtained from Sigma Chemical Co., (St. Louis, MO). Where applicable, proteins were labeled with ${ }^{125}$ I using the Iodogen method (24).

Platelet preparation. Blood was drawn from normal volunteers or consenting patients and anticoagulated in EDTA. After centrifugation at $110 \mathrm{~g}$, the platelet-rich plasma was removed and the platelets washed three times in GVB-EDTA.

Complement lysis sensitivity of patient erythrocytes. The percentage of abnormal erythrocytes in the blood of patients with PNH was assessed using the complement lysis sensitivity (CLS) test (6). This assay measures the sensitivity of erythrocytes to lysis by antibody and complement. PNH II erythrocytes have CLS values between 4 and 10. PNH III erythrocytes have CLS values $>20$.

Determination of DAF-negative platelet populations by flow cytometry Washed PNH or normal donor platelets were reacted with rabbit antiDAF or nonimmune rabbit serum, washed and then incubated with FITC affinity-purified $F\left(a b^{\prime}\right)_{2}$ goat anti-rabbit IgG. Stained platelets were fixed in $1 \%$ formalin before fluorescence analysis. Platelets from normal donors were run with each group of PNH platelets.

Cell-associated fluorescence was measured using a cytofluorograph (model 50H, Ortho Diagnostic Systems Inc., Raritan, NJ). Platelets were illuminated with the 488-nm line of an argon ion laser and the rightangle light scatter focused onto appropriate fiber optics using a 32X/ 0.40 NA objective (E. Leitz, Inc., Rockleigh, NJ) mounted in a carrier of local design. Fluorescence was measured behind a 515-530-nm band pass filter. Analysis was restricted to signals from single platelets by gating the fluorescence signals on the basis of a right angle versus forward scatter cytogram. The amplifiers were set in linear mode and the data were analyzed using the software in an Ortho 2140 data handling system. For statistical analysis of the histograms, two regions were defined. The first, region 1, represents channels $1-999$, to exclude unweighted off-scale data in channel 1000 from statistical analysis. The lower limits of region 2 are defined by the right shoulder of the histogram of the platelets incubated with nonimmune rabbit serum and FITC-conjugated second antibody (negative control).

Measurement of total platelet DAF. To determine whether platelets contain internal pools of DAF that might affect convertase stability, Western blot analysis was performed on the platelets of the PNH patients in the study. Washed platelets were solubilized in nonreducing SDS Laemmli polyacrylamide gel electrophoresis sample buffer $(0.125 \mathrm{M}$ Tris, $4 \%$ SDS, and $20 \%$ glycerol [pH 6.8]) and $50 \mu \mathrm{g}$ total protein was loaded per lane. After electrophoresis into $7.5 \%$ polyacrylamide gels, the proteins were transferred onto nitrocellulose paper using the method of Towbin et al. (25). The nitrocellulose was probed first with rabbit anti-DAF or nonimmune rabbit serum and second with [ $\left.{ }^{125} \mathrm{I}\right]$ staphylococcal protein A. The paper was dried and autoradiographed.

Measurement of nephritic factor-stabilized C3 convertase activity. To measure the activity of an alternative pathway $\mathrm{C} 3$ nephritic factorstabilized $\mathrm{C} 3$ convertase on the platelet surface, $5 \times 10^{8}$ platelets in GVB-EDTA were first incubated with $1 \mathrm{mg} \mathrm{C} 3$ and CoVF-factor $\mathrm{Bb}$ complexes (CoVFBb) for $30 \mathrm{~min}$ at $37^{\circ} \mathrm{C}$. The CoVFBb complexes were prepared by incubating $50 \mu \mathrm{g} \mathrm{CoVF}$ in $5 \mathrm{mM} \mathrm{MgCl}_{2}$ with $50 \mu \mathrm{g}$ factor $B$ and sufficient crude factor $\mathrm{D}$ to convert all the factor $\mathrm{B}$ to $\mathrm{Bb}$. The magnesium was chelated with EDTA before adding the CoVF complexes to the platelets. After a 30-min incubation, these platelets (PC3b) were washed in GVB-EDTA three times and a sample removed to measure platelet-bound $\mathrm{C} 3 \mathrm{~b}$. The PC3b were then washed into $\mathrm{GVB}^{+}$and exposed to factor $\mathrm{B}$, factor $\mathrm{D}$, and $\mathrm{C} 3$ nephritic factor for $10 \mathrm{~min}$ at $37^{\circ} \mathrm{C}$. After one wash with $\mathrm{GVB}^{+}$, the platelets were incubated with $1 \mathrm{mg} \mathrm{C} 3$ for 30 min at $37^{\circ} \mathrm{C}$. After three washes with GVB-EDTA, these platelets (PC3bBbC3NeF) were assayed for platelet-bound C3b.

$A$ radiolabeled monoclonal antibody-binding assay was used to measure the amount of $\mathrm{C} 3 \mathrm{~b}$ deposited on the platelet surface under the above conditions. Equal volumes of ${ }^{125} \mathrm{I}$-labeled anti-C $3 \mathrm{c}$ and washed platelets were incubated for $30 \mathrm{~min}$ at room temperature. Aliquots of the platelet and antibody suspension were centrifuged through phthalate esters (Fisher Scientific Co., Pittsburgh, PA) (1.5 parts butyl phthalate/ 1 part bis [2-ethylhexyl] phthalate) to separate bound from unbound antibody. Nonspecific antibody binding was defined as that antibody binding to platelets exposed only to $\mathrm{C} 3$, but not CoVF complexes in the first step (PC3). The determination of molecules of antibody bound per platelet was made from a knowledge of the specific activity of the antibody and the platelet count. A conversion ratio was calculated as follows:

molecules bound/PC $3 \mathrm{bBbC} 3 \mathrm{NeF}$ - molecules bound/PC 3b

molecules bound/PC $3 \mathrm{~b}-$ molecules bound/PC 3

Measurement of platelet factor $\mathrm{H}$ release. $5 \times 10^{8}$ washed platelets in $\mathrm{GVB}^{+}$were incubated with $1 \mathrm{mg} \mathrm{C} 3,50 \mu \mathrm{g}$ factor $\mathrm{B}$, and crude factor $\mathrm{D}$ for $30 \mathrm{~min}$ at $37^{\circ} \mathrm{C}$. Immediately after washing three times in PBS, the platelets were resuspended in $1 \mathrm{ml}$ PBS containing $1 \%$ paraformaldehyde (PFA) and incubated at room temperature for $1 \mathrm{~h}$. After washing three times in GVB-EDTA to block unreacted aldehyde groups, the platelets were stained for flow cytometry as described above using goat anti-factor $\mathrm{H}$ or rabbit anti-C3c (both from Calbiochem-Behring Corp.) and the appropriate FITC-conjugated second antibodies. Control platelets were prepared using PFA-fixed platelets that had been exposed to complement components. Controls for antibody binding were performed using nonimmune sera.

Thrombin-stimulated factor $\mathrm{H}$ release was assessed by treating platelets at $5 \times 10^{8} / \mathrm{ml}$ in GVB-EDTA with $100 \mathrm{U} / \mathrm{ml}$ thrombin for $20 \mathrm{~min}$ at $37^{\circ} \mathrm{C}$. The platelets were then fixed in PFA and stained as described above.

Quantitation of platelet factor $H$. The amount of factor $\mathrm{H}$ released by thrombin-stimulated or detergent-solubilized platelets was measured by a radioimmunoassay described in detail elsewhere (Devine, D. V., and W. F. Rosse, manuscript in preparation). Briefly, microtiter plate wells were coated with a monoclonal antibody to human factor $\mathrm{H}$ (Genzyme Corp., Boston, MA), supernates from thrombin-stimulated platelets or Triton X-100-solubilized platelets were added to the wells. After washing the plate, ${ }^{125}$ I-labeled polyclonal anti-factor $\mathrm{H}$ was added to each well. The bound cpm were measured using a scintillation well-type gamma counter. The amount of factor $\mathrm{H}$ per $10^{8}$ platelets was determined by comparison with a standard curve prepared using purified serum factor $\mathrm{H}$.

Uptake of membrane attack complexes from serum. We were interested in determining if the platelets from patients with PNH take up membrane attack complexes under the conditions of reactive lysis as do PNH III erythrocytes. CoVFBb complexes were prepared exactly as described above. $5 \times 10^{8}$ platelets in GVB-EDTA were incubated with CoVF complexes and EDTA-chelated normal human serum ( 9 parts serum/1 part $0.2 \mathrm{M}$ EDTA [pH 7.2]) for $30 \mathrm{~min}$ at $37^{\circ} \mathrm{C}$. After three washes in GVB-EDTA, platelet-bound C5b-9 was assessed by ${ }^{125}$ I-labeled monoclonal anti-poly C9 binding as described above. The $t$ test was used for statistical analysis of antibody-binding studies (26).

${ }^{111}$ In-labeled platelet survival studies. Platelet survival studies were performed on patients after obtaining written informed consent. The protocol was approved by the Duke University Medical Center Human Research Committee. Briefly, platelets were isolated and labeled according to the method of Thakur et al. (27), as modified by Heaton et al. (28). There was no loss of platelets during the labeling procedure. $200 \mu \mathrm{Ci}$ of "11'In-labeled autologous platelets were injected intravenously and serial blood samples were obtained $15 \mathrm{~min}$ and $2 \mathrm{~h}$ after injection, then every $12 \mathrm{~h}$ thereafter for $4 \mathrm{~d}$. To estimate mean survival time, data were analyzed using the maximum likelihood estimate of the integer-ordered gamma function as recommended by the International Committee for Stan- 
dardization in Hematology (29). Platelet turnover was calculated according to the formula:

platelets $/ \mu \mathrm{l}$ per $\mathrm{h}=\frac{\text { platelet count } / \mu \mathrm{l}}{\text { life } \operatorname{span}(\mathrm{h})} \times \frac{90 \%}{\text { initial recovery }}(30)$

Images of the anterior and posterior chest and anterior and posterior abdomen were obtained $24 \mathrm{~h}$ after injection using a large crystal scintillation camera fitted with a medium energy collimator. Both gamma photon peaks of ${ }^{111}$ In (at 173 and $247 \mathrm{keV}$ ) were summed and each image was acquired for $300 \mathrm{~s}$.

\section{Results}

We have studied the platelets of 20 patients with $\mathrm{PNH}$ of whom 8 have been examined multiple times. The binding of anti-DAF antibody to platelets was used to measure the percentage of DAFdeficient platelets in each patient. This percentage was then compared with the percentage of complement-sensitive erythrocytes as measured by the CLS test (Fig. 1). For each patient studied, there was a greater population of abnormal (DAF-deficient) platelets than abnormal erythrocytes. The binding of anti-DAF to normal donor platelets was highly heterogeneous (Fig. $2 A$ ). Most patients had platelets which bound little if any anti-DAF (Fig. $2 C$ ). Even in those four PNH patients whose platelets showed significant anti-DAF binding there was never the intensity of staining seen in normal platelets (Fig. $2 \mathrm{~B}$ ).

By Western blot analysis, the platelets of patients with $>80 \%$ DAF-negative platelets by fluorescence analysis did not contain cryptic pools of DAF (Fig. 3). Using this method, DAF was readily detected in normal platelets (Fig. 3, lane 1).

The activity of the alternative pathway $\mathrm{C} 3$ convertase was measured on the surface of normal and PNH platelets to determine the effect of DAF deficiency on the regulation of this enzyme complex. PNH platelets did not bind fluid phase $\mathrm{C} 3 \mathrm{~b}$ more readily than normal platelets because similar amounts of monoclonal anti-C3c bound to normal donor or PNH platelets, which were reacted with fluid phase CoVF-factor $\mathrm{Bb}$ complexes and C3 (Table I). C3 nephritic factor-stabilized convertases were established at these $\mathrm{C} 3 \mathrm{~b}$ sites and the functional activity of these

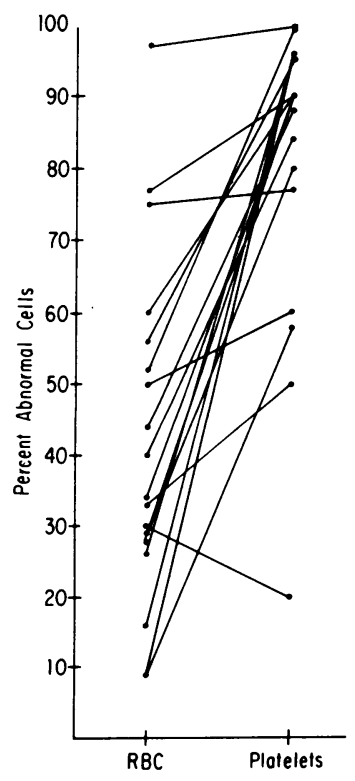

Figure 1. Percentage of abnormal erythrocytes and abnormal platelets for a given patient with $\mathrm{PNH}$. The percentage of abnormal erythrocytes was determined by the CLS test of Rosse and Dacie (6). The percentage of abnormal platelets was determined by measuring the amount of platelets that failed to stain with antibody to DAF. This was achieved by fluorescence flow cytometry.

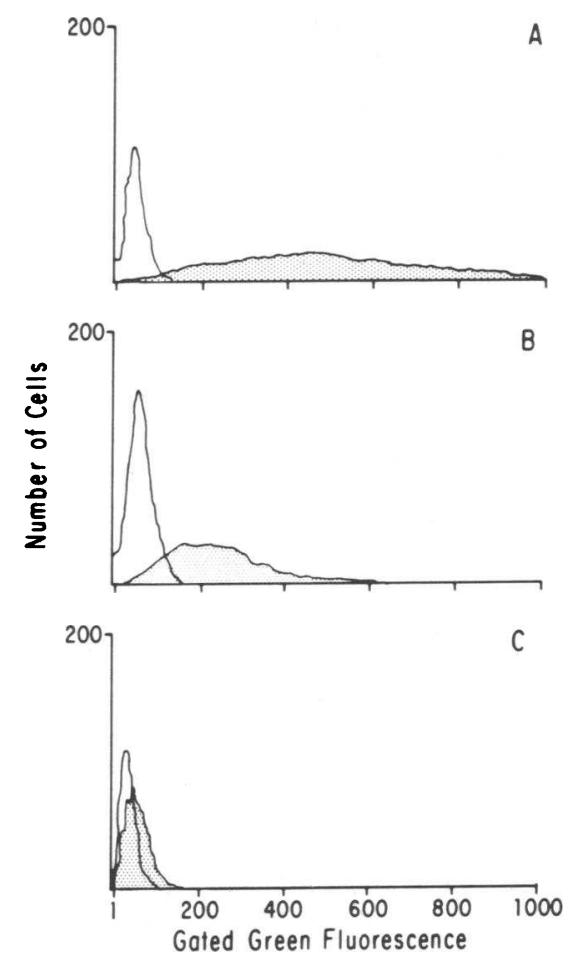

Figure 2. Cytograms of staining patterns of normal and PNH platelets with rabbit antibody to DAF. Gated green fluorescence is shown on a linear scale. Anti-DAF staining is shown in the stippled curves while nonimmune rabbit serum controls are not stippled. $A$, staining pattern of normal platelets. Note that the staining is highly heterogeneous. $B$, staining pattern seen in 4 of 20 patients. Note that there are no platelets found in the higher intensity channels on the right. $C$, staining pattern seen in most of the PNH patients examined. There was little, if any, significant staining with the anti-DAF antibody.

convertases was measured. The activity of these $\mathrm{C} 3$ convertases on the platelets of 13 normal donors as defined by the conversion ratio was 9.1 ( $\mathrm{SD}=3.3$ ). Values $>2 \mathrm{SDs}$ above the mean of the activity on normal donors were considered elevated. Not all patients with PNH had elevated activity of the C3 convertases formed on the platelet surface (Fig. 4). 10 of 19 patients had normal C3 convertase activity, while 9 had elevated activity.

C3 convertase activity was also measured on the platelets of four patients without $\mathrm{C} 3$ nephritic factor stabilization. Although the conversion ratios for both normal and PNH platelets were lower than those obtained with stabilized convertases, the pattern of elevated convertase activity on the platelets of only some of the PNH patients was consistent with the results of experiments with stabilized C3 convertases. Three of the four patients had elevated convertase activity with a stabilized convertase. Without the addition of $\mathrm{C} 3$ nephritic factor, the convertase activity was $2.9,3.6$, and 4.7 times that seen on normal platelets run in parallel experiments. The other patient had platelets on which a stabilized $\mathrm{C} 3$ convertase had normal activity. When the experiment was performed with this person's platelets without $\mathrm{C} 3$ nephritic factor, the convertase activity was 0.9 times that of the normal platelet controls.

Because the presence of DAF on the platelets could account for the apparent regulation of the $\mathrm{C} 3$ convertase activity on the platelets of some $\mathrm{PNH}$ patients, the $\mathrm{C} 3$ convertase activity was compared with the percentage of DAF-negative platelets (Fig. 


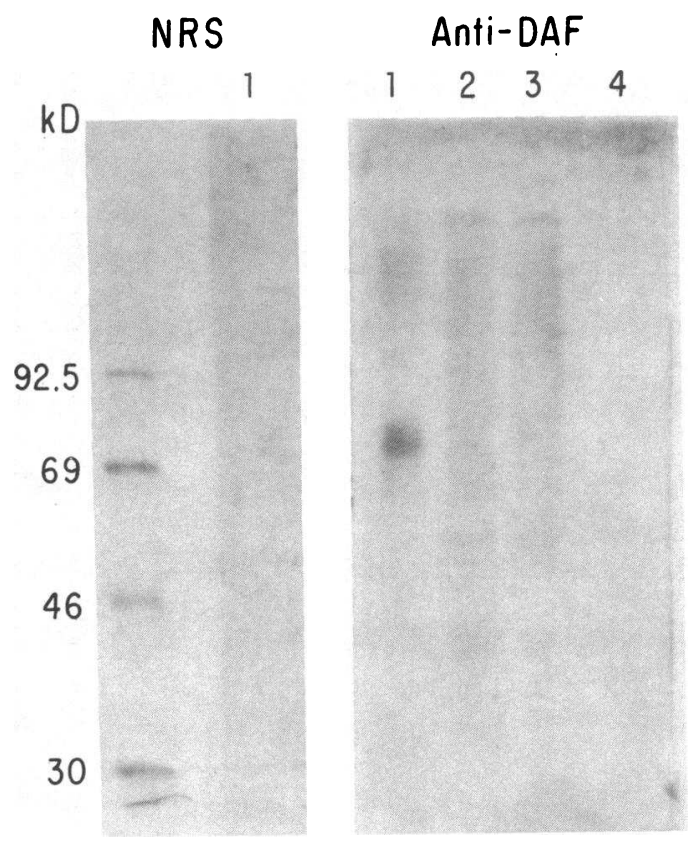

Figure 3. Western blot analysis of platelet DAF. Washed platelets from a normal donor or PNH patients with $>80 \%$ DAF-negative platelets by flow cytometry were electrophoresed on SDS-polyacrylamide gel electrophoresis and transferred to nitrocellulose paper. The nitrocellulose was incubated with nonimmune rabbit serum or rabbit anti-DAF, then with ${ }^{125}$ I-labeled staphylococcal protein A. An autoradiograph of the nitrocellulose paper is shown here. Normal donor platelets were electrophoresed in Lane 1. Lanes 2-4 contain platelets from three different PNH patients.

5). 8 of the 10 patients with normal convertase activity had $>70 \%$ DAF-negative platelets by flow cytometry analysis.

When platelets were incubated with $\mathrm{C} 3$, factor $\mathrm{B}$, factor $\mathrm{D}$, $\mathrm{CoVF}$, and magnesium, C3b was bound to the platelet surface. Some of the $\mathrm{C} 3 \mathrm{~b}$ binds factor $\mathrm{B}$ to form the alternative pathway C3 convertase on the platelet surface. The deposition of C3 by this technique triggered the release of factor $\mathrm{H}$ from the platelet. Factor $\mathrm{H}$ then became bound to the platelet surface and was detected by flow cytometry. Fig. 6 shows factor $\mathrm{H}$ release from normal platelets in response to $\mathrm{C} 3$ deposition. Very similar staining patterns were seen when $\mathrm{PNH}$ platelets contained platelet-bound C3 (Fig. 7). This finding was observed in the platelets of patients with either PNH II or PNH III erythrocytes. Thrombin-stimulated platelets also released factor $H$ into the sur-

Table I. Deposition of C3 onto PNH and Normal Platelets from Fluid Phase

\begin{tabular}{ll}
\hline Platelets & $\begin{array}{l}\text { Molecules of monoclonal anti-C3c } \\
\text { bound/platelet }\end{array}$ \\
\hline & mean $\pm S D$ \\
Normal donor platelets $(n=13)$ & $2590 \pm 1362$ \\
PNH patient platelets $(n=14)$ & $2385 \pm 1059^{*}$
\end{tabular}

Reactive lysis conditions were created using CoVFBb complexes and purified C3. Platelet-bound C3 was measured using ${ }^{125}$ I-labeled monoclonal anti-C3c.

* Not significantly different from normal $(P>0.5)$.

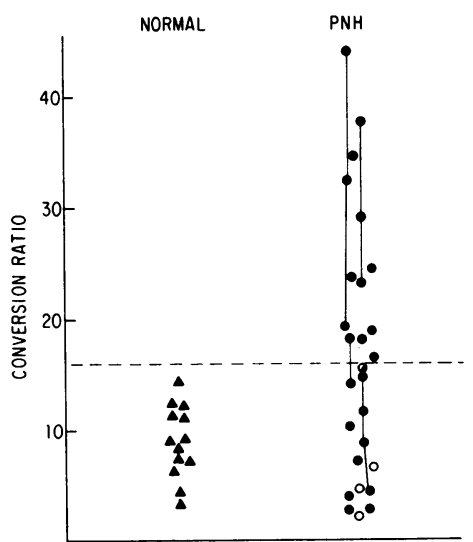

Figure 4. Alternative pathway $\mathrm{C} 3$ convertase activity on normal and PNH platelets. After creating nephritic factor-stabilized C3 convertases on the surface of the platelet using purified components, the platelets were exposed to additional $\mathrm{C} 3$. The $\mathrm{C} 3$ conversion ratio represents the amount of $\mathrm{C} 3$ bound per $\mathrm{C} 3$ convertase created. Platelet-bound $\mathrm{C} 3$ was assessed by ${ }^{125} \mathrm{I}-\mathrm{la}-$ beled monoclonal anti-C3c antibody binding. Lines

connect measurements obtained on the same patient. For a given patient, several months separate each measurement. Filled circles, patients with PNH III erythrocytes. Open circles, patients with PNH III erythrocytes. Half-filled circle, a patient with both PNH II and PNH III erythrocytes.

rounding medium; however, factor $\mathrm{H}$ did not bind back to the platelet surface in the absence of platelet-bound C3b (Fig. 6).

We have quantitated the amount of factor $\mathrm{H}$ released from the platelets of five patients with PNH by thrombin or detergent solubilization. The platelets of two of these patients had elevated C3 convertase activity. While thrombin-stimulated normal platelets released an average of $50 \mathrm{ng}$ factor $\mathrm{H} / 10^{8}$ platelets, thrombin-stimulated PNH platelets released markedly lower amounts of factor $\mathrm{H}$. In response to thrombin stimulation, the platelets from $\mathrm{PNH}$ patients with normal $\mathrm{C} 3$ convertase activity released 14,15 , and $17 \mathrm{ng}$ factor $\mathrm{H} / 10^{8}$ platelets, whereas the platelets from two patients with elevated $\mathrm{C} 3$ convertase activity released 4 and $6 \mathrm{ng}$ factor $\mathrm{H} / 10^{8}$ platelets. However, radioimmunoassays of Triton X-100-solubilized platelets from the same platelet preparations demonstrated that the total factor $\mathrm{H}$ contained in the platelets of these two patients was 19 and $24 \mathrm{ng} /$ $10^{8}$ platelets. The total amount of factor $\mathrm{H}$ detected in detergentsolubilized normal platelets is virtually identical to that amount released by thrombin stimulation (Devine, D. V., and W. F. Rosse, manuscript in preparation).

When platelets were reacted with CoVF-treated EDTAserum (reactive lysis), neither normal or PNH platelets took up membrane attack complexes from the serum. The amount of monoclonal anti-poly $\mathrm{C} 9$ binding to $\mathrm{PNH}$ platelets was not statistically different from the binding to normal platelets $(t=0.44$,

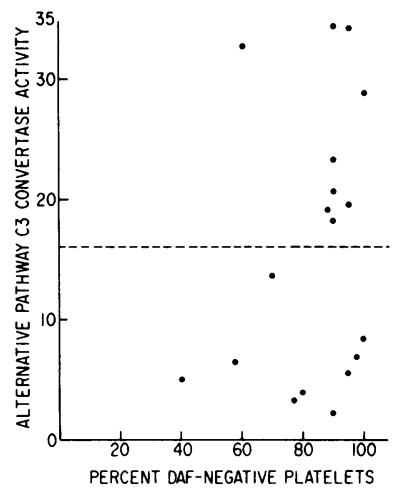

Figure 5. Comparison of alternative pathway $\mathrm{C} 3$ convertase activity and the percentage of DAF-negative platelets for patients with PNH. C3 convertase activity was assessed as described in Fig. 4 . The percentage of DAF-negative platelets was measured using fluorescence flow cytometry. 


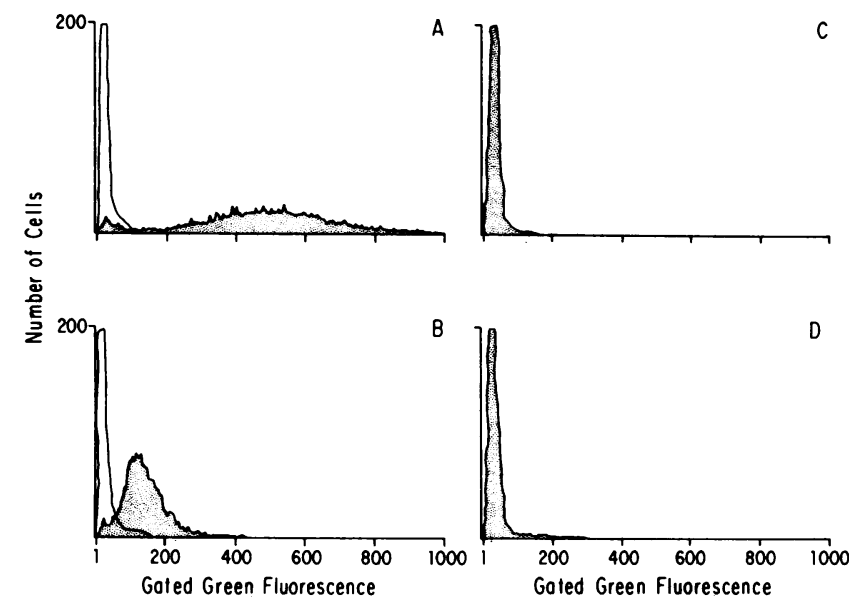

Figure 6. Flow cytometric analysis of platelet bound $\mathrm{C} 3$ and factor $\mathrm{H}$ on normal platelets. The binding of anti-C3 $(A)$ or anti-factor $\mathrm{H}(B-$ $D$ ) are indicated by the stippled curves. Nonimmune serum control curves are not stippled. Platelets were incubated with CoVF, C3, factor $\mathrm{B}$, factor $\mathrm{D}$, and magnesium $(A$ and $B)$, with thrombin $(C)$ or with buffer alone $(D)$. The anti-factor $\mathrm{H}$ and nonimmune serum curves are coincident in $C$ and $D$.

$P>0.5$ ) (Fig. 8). However, the monoclonal anti-poly C9 readily detected the increased uptake of membrane attack complexes by PNH III erythrocytes under identical reactive lysis conditions. In addition, PNH platelets exposed to reactive lysis conditions bound ${ }^{125} \mathrm{I}$-labeled anti-C $3 \mathrm{c}$ in amounts similar to normal platelets (data not shown).

Of the eight patients who participated in ${ }^{111}$ In-labeled platelet survival studies, five had normal platelet survival, while three had decreased survival (Table II). Of the three with decreased
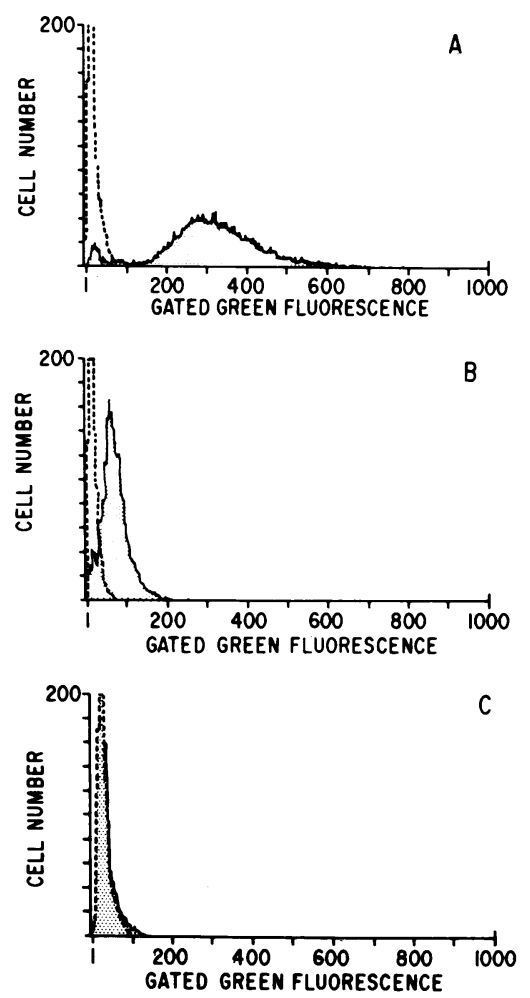

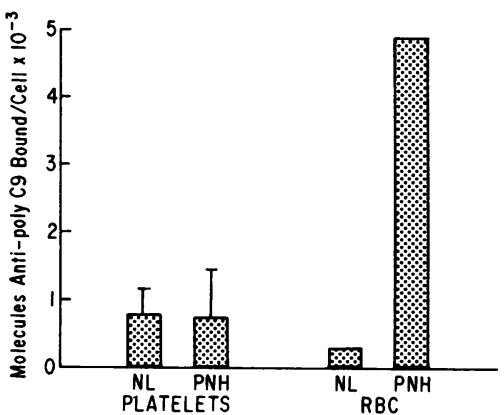

Figure 8. Uptake of membrane attack complexes by normal and PNH erythrocytes and platelets under the conditions of reactive lysis. Washed platelets or erythrocytes were exposed to CoVF-factor B complex-treated EDTAchelated serum. The uptake of membrane attack complexes was measured by ${ }^{125}$ I-labeled monoclonal anti-poly $\mathrm{C} 9$ antibody binding. This monoclonal antibody recognizes a neoantigen expressed by polymerized C9. Normal platelets bound a mean of 766 molecules of antipoly $\mathrm{C}$ /platelet $(\mathrm{SD}=412 ; n=9$ ), while $\mathrm{PNH}$ platelets bound 720 molecules anti-poly C9/platelet (SD $=768 ; n=11)$. The PNH erythrocytes shown in this experiment contained $>95 \%$ PNH III cells.

survival, two had splenic enlargement. The percentage of DAFnegative platelets were measured in four of these patients. Three had $>90 \%$ DAF-negative platelets and one had 77\% DAF-negative platelets. Of these patients, two had normal platelet survival and turnover times. The other two were the patients with splenic enlargement.

\section{Discussion}

The abnormal interactions of complement with erythrocytes in PNH cause increased destruction of red cells. This phenomenon is readily demonstrated by the increased sensitivity of PNH cells to lysis by antibody and complement in vitro (6). In vivo, the activation of complement by the alternative pathway is the most likely cause of red cell destruction (1). Aster and Enright demonstrated that the platelets of patients with $\mathrm{PNH}$ are more readily lysed by complement in the presence of complement-fixing anti-

Table II. ${ }^{111}$ In-labeled Platelet Studies in PNH Patients

\begin{tabular}{|c|c|c|c|c|c|}
\hline Patient & $\begin{array}{l}\text { Platelet } \\
\text { count } / \mu \mathrm{l}\end{array}$ & Survival & Recovery & Turnover & $\begin{array}{c}\text { DAF- } \\
\text { negative } \\
\text { platelets }\end{array}$ \\
\hline & & $h$ & $\%$ & $p l t / \mu l / h$ & $\%$ \\
\hline $1^{*}$ & 113,000 & 106 & 25 & 3837 & 95 \\
\hline 2 & 12,000 & 157 & 81 & 85 & N.D. ${ }^{\ddagger}$ \\
\hline 3 & 172,000 & 176 & 65 & 1349 & 90 \\
\hline 4 & 231,000 & $>200$ & 74 & 992 & N.D. \\
\hline 5 & 76,000 & $>200$ & 55 & 612 & N.D. \\
\hline 6 & 309,000 & 124 & 65 & 3439 & N.D. \\
\hline $7 *$ & 375,000 & 92 & 27 & $>4000$ & 90 \\
\hline 8 & 567,000 & 200 & N.D. & 1634 & 77 \\
\hline Normal & $200-300,000$ & $180-200$ & $60-70$ & $1000-1500$ & 0 \\
\hline
\end{tabular}

Platelets were isolated from the patient's peripheral blood and labeled with "'In oxine. After the labeled platelets were given back to the patient, blood samples were drawn at $15 \mathrm{~min}, 2 \mathrm{~h}$, and every $12 \mathrm{~h}$ after injection. Survival was calculated using the maximum likelihood estimate of the integer-ordered gamma function (29).

* Splenomegaly present.

¥ Not done. 
platelet antibody (18) than are normal platelets. The interactions of platelets with the alternative pathway of complement are not as well understood. Studies from this laboratory using CoVFtreated whole serum and quantitative antiglobulin consumption assays for platelet-bound $\mathrm{C} 3$ indicate that $\mathrm{PNH}$ platelets bind more C3 than do normal platelets (31).

To study the interactions of normal and PNH platelets with complement components in the absence of other serum proteins, we used purified components and monoclonal antibodies specific for the $\mathrm{C} 3 \mathrm{c}$ region of $\mathrm{C} 3$. We have demonstrated that the $\mathrm{C} 3$ convertase activity on the platelets of many patients with $\mathrm{PNH}$ was not greater than that on normal platelets. This could not be attributed to the presence of DAF either on the platelet surface or in internal pools that might be expressed when complement binds to the platelet. The platelets of 16 of 20 patients examined were nearly all DAF-deficient. Because platelets that were lacking in DAF did not bind abnormal amounts of C3, DAF may not play as pivotal a role in the regulation of the alternative pathway C3 convertase on the platelet as it does on the red blood cell surface $(11,12)$. However, DAF may be crucial to the regulation of the classical pathway $\mathrm{C} 3$ convertase, $\mathrm{C} 4 \mathrm{~b} 2 \mathrm{a}$, on the platelet surface. The absence of this regulatory protein on PNH platelets may explain the increased susceptibility of the PNH platelet to lysis by antibody and complement $(18,31)$. In fact, preliminary data obtained on some of the same patients reported in this study indicate that when complement is activated by antibody in a whole serum system, PNH platelets bind both more $\mathrm{C} 3$ and more $\mathrm{C} 9$ than normal platelets. The hypothesis that DAF is not crucial in the regulation of the alternative pathway $\mathrm{C} 3$ convertase on platelets is further supported by the observation that when C3 was deposited onto the surface of platelets via the alternative pathway, the platelets of both normal donors and patients with PNH released factor $\mathbf{H}$, a plasma protein that performs a similar function to DAF. Factor $\mathrm{H}$ became bound to the platelet surface only when $\mathrm{C} 3$ was present on the platelet. Factor $\mathrm{H}$ released by thrombin stimulation did not bind to the platelet surface in the absence of platelet-bound C3. The platelet, therefore, appears to have a second mechanism to regulate surface-bound alternative pathway $\mathrm{C} 3$ convertases. Other complement components in addition to factor $\mathrm{H}$ (32) have been described in platelets, including $\mathrm{Cl}$ inhibitor (33) and factor $\mathrm{D}$ (32). Whereas the intracellular localization of factor $\mathrm{H}$ has not yet been determined, the other two complement components appear to reside in the platelet alpha granules.

In PNH platelets, the total amount of factor $\mathrm{H}$ present appears to be lower than that in normal platelets. The factor $\mathrm{H}$ released by thrombin-stimulated platelets of two patients with increased C 3 convertase activity was markedly deficient, although the total amount of factor $\mathrm{H}$ contained in these platelets was equivalent to that amount readily released from $\mathrm{PNH}$ platelets with normal C3 convertase activity. In addition, we report elsewhere that the inhibition of factor $\mathrm{H}$ release from normal platelets markedly enhances $\mathrm{C} 3$ convertase activity. Therefore, it appears that some PNH platelets may be unable to release a sufficient amount of factor $\mathbf{H}$ to regulate the activity of the alternative pathway $\mathrm{C} 3$ convertase. The reason that this occurs in only some of the PNH patients studied remains to be elucidated.

Previous studies from both our laboratory (31) and others (34) on the interaction of the alternative pathway of complement with the platelets in PNH were all performed using whole serum systems. The data reported in this study support the observation of Zimmerman and Kolb (34) that the platelets in PNH do not take up more C3 than normal platelets when exposed to CoVFtreated serum. However, these workers reported an increased uptake of $\mathrm{C} 8$, presumably in the form of membrane attack complex by the platelets of one PNH patient under the same conditions. We did not see any increase in the uptake of membrane attack complexes under our experimental conditions, which differed somewhat from those of Zimmerman and Kolb (34), particularly with regard to the presence of EDTA in the reaction mixture. In whole serum systems, the interactions of the platelets with activated coagulation factors, especially thrombin, as well as with complement components must be taken into consideration. The presence of thrombin has been shown to markedly affect the interaction of platelets with complement $(35,36)$.

Platelets can actively rid themselves of surface-bound membrane attack complexes by a calcium-dependent shedding process similar to the patching and capping phenomena seen in nucleated cells (37). In this investigation, this process was inhibited by performing the experiments in the presence of EDTA. Under these conditions, we have demonstrated that the platelets from patients with PNH III erythrocytes do not take up membrane attack complexes that are generated in the fluid phase. However, the PNH III erythrocyte will take up large amounts of this complex resulting in cell lysis $(9,10)$. Because this is most likely the mechanism that contributes to the severely shortened in vivo survival of the PNH III erythrocyte, it follows that we and others (18) have found in vivo platelet survival was normal in most PNH patients. This is reflected in the observed percentages of abnormal erythrocytes and abnormal platelets in the peripheral blood of patients with PNH. Because the erythrocyte lifespan is shortened and the platelet lifespan is normal or nearly so, the percentage of abnormal platelets may more accurately reflect the extent of proliferation of the abnormal PNH clone. Shortened platelet survival time was only seen in those patients who had splenomegaly or in the one patient in the study who was entering an aplastic crisis.

In addition, the PNH III erythrocyte is markedly sensitive to lysis by complement because the cells will bear fewer of the membrane attack complexes of complement than normal erythrocytes before they lyse. Although we do not have direct evidence that this is also the case for PNH platelets, it would explain the observation that PNH platelets are more susceptible to complement lysis when complement is activated at the platelet surface, e.g., by anti-platelet antibody (18).

\section{Acknowledgments}

We acknowledge the assistance of Dr. R. Edward Coleman with the platelet survival studies. Our thanks to Frank Cornew for performing the flow cytometry analyses.

This work was supported by National Institutes of Health grant AM31379 awarded to Dr. Rosse.

\section{References}

1. Rosse, W. F., and C. J. Parker. 1985. Paroxysmal nocturnal hemoglobinuria. Clin. Haematol. 14:105-125.

2. Ham, T. H., and J. H. Dingle. 1939. Studies on destruction of red blood cells. II. Chronic hemolytic anemia with paroxysmal nocturnal hemoglobinuria: certain immunological aspects of the hemolytic mechanism with special reference to serum complement. J. Clin. Invest. 18: 657-672.

3. Peytremann, R., R. S. Rhodes, and R. C. Hartmann. 1972. Thrombosis in paroxysmal nocturnal hemoglobinuria ( $\mathrm{PNH}$ ) with particular reference to progressive, diffuse hepatic venous thrombosis. Semin. Hematol. 5:115-136. 
4. Parker, C. J., P. J. Baker, and W. F. Rosse. 1982. Increased enzymatic activity of the alternative pathway convertase when bound to the erythrocytes of paroxysmal nocturnal hemoglobinuria. J. Clin. Invest. 69:337-346

5. Pangburn, M. K., R. D. Schreiber, J. S. Trombold, and H. J. Muller-Eberhard. 1983. Paroxysmal nocturnal hemoglobinuria: defect in the factor $\mathrm{H}$-like functions of the abnormal erythrocytes. J. Exp. Med. 157:1971-1980.

6. Rosse, W. F., and J. V. Dacie. 1966. Immune lysis of normal human and paroxysmal nocturnal hemoglobinuria (PNH) red blood cells. I. The sensitivity of PNH red cells to lysis by complement and specific antibody. J. Clin. Invest. 45:736-748.

7. Packman, C. H., S. I. Rosenfield, D. E. Jenkins, Jr., P. A. Thiem, and J. P. Leddy. 1979. Complement lysis of human erythrocytes. Differing susceptibility of two types of paroxysmal nocturnal hemoglobinuria cells to C5b-9. J. Clin. Invest. 64:428-433.

8. Roualt, T. A., W. F. Rosse, S. Bell, and J. Shelburne. 1978. Differences in the terminal steps of complement lysis of normal and paroxysmal nocturnal hemoglobinuria red cells. Blood. 51:325-330.

9. Gotze, O., and H. J. Muller-Eberhard. 1970. Lysis of erythrocytes by complement in the absence of antibody. J. Exp. Med. 132:898-915.

10. Parker, C. J., T. Wiedmer, P. J. Sims, and W. F. Rosse. 1985. Characterization of the complement sensitivity of paroxysmal nocturnal hemoglobinuria erythrocytes. J. Clin. Invest. 75:2074-2084.

11. Nicholson-Weller, A., J. P. March, S. I. Rosenfield, and K. F. Austen. 1983. Affected erythrocytes of patients with paroxysmal nocturnal hemoglobinuria are deficient in the complement regulatory protein, decay accelerating factor. Proc. Natl. Acad. Sci. USA. 80:5066-5070.

12. Pangburn, M. K., R. D. Schreiber, and H. J. Muller-Eberhard. 1983. Deficiency of an erythrocyte membrane protein with complement regulatory activity in paroxysmal nocturnal hemoglobinuria. Proc. Natl. Acad. Sci. USA. 80:5430-5434.

13. Nicholson-Weller, A., D. B. Spicer, and K. F. Austen. 1985 Deficiency of the complement regulatory protein, "decay accelerating factor", on membranes of granulocytes, monocytes, and platelets in paroxysmal nocturnal hemoglobinuria. $N$. Engl. J. Med. 312:1091-1097.

14. Hoffman, E. M. 1969. Inhibition of complement by a substance isolated from human erythrocytes. II. Studies on the site and mechanism of action. Immunochemistry. 6:405-419.

15. Nicholson-Weller, A., J. Burge, D. T. Fearon, P. F. Weller, and K. F. Austen. 1982. Isolation of a human erythrocyte membrane glycoprotein with decay-accelerating activity for the $\mathrm{C} 3$ convertases of the complement system. J. Immunol. 129:184-189.

16. Medof, M. E., T. Kinoshita, and V. Nussenzweig. 1984. Inhibition of complement activation on the surface of cells after incorporation of decay-accelerating factor (DAF) into their membranes. J. Exp. Med. 160:1558-1578.

17. Medof, M. E., W. F. Rosse, T. Kinoshita, R. Silber, and V. Nussenzweig. 1985. Partial correction of the paroxysmal nocturnal hemoglobinuria (PNH) hemolytic defects with decay accelerating factor (DAF). Clin. Res. 33:554. (Abstr.)

18. Aster, R. H., and S. E. Enright. 1969. A platelet and granulocyte membrane defect in paroxysmal nocturnal hemoglobinuria. Usefulness for the detection of platelet antibodies. J. Clin. Invest. 48:1 199-1210.

19. Ballow, M., and C. G. Cochrane. 1969. Two anticomplementary factors in cobra venom: hemolysis of guinea pig erythrocytes by one of them. J. Immunol. 103:944-952.
20. Tack, B. F., and J. W. Prahl. 1976. Third component of complement: purification from plasma and physicochemical characterization. Biochemistry. 15:4513-4521.

21. Lambris, J. D., N. J. Dobson, and G. D. Ross. 1980. Release of endogenous $\mathrm{C} 3 \mathrm{~b}$ inactivator from lymphocytes in response to triggering membrane receptors for $\beta 1 \mathrm{H}$ globulin. J. Exp. Med. 152:1625-1644.

22. Schreiber, R. D., O. Gotze, and H. J. Muller-Eberhard. 1976. Nephritic factor: its structure and function and its relationship to initiating factor of the alternative pathway. Scand. J. Immunol. 5:703-713.

23. Falk, R. J., A. P. Dalmasso, Y. Kim, C. H. Tsai, J. I. Scheinman, H. Gewurz, and A. F. Michael. 1983. Neoantigen of the polymerized ninth component of complement. Characterization of a monoclonal antibody and immunohistochemical localization in renal disease. J. Clin. Invest. 72:560-573.

24. Fraker, P. J., and J. C. Speck. 1978. Protein and cell iodinations with a sparingly soluble chloramide 1,3,4,5-tetrachloro-3,6-diphenylglycuril. Biochem. Biophys. Res. Commun. 80:849-857.

25. Towbin, H., T. Staehlin, and J. Gordon. 1979. Electrophoretic transfer of proteins with polyacrylamide gels to nitrocellulose sheets: procedure and some applications. Proc. Natl. Acad. Sci. USA. 76:43504354.

26. Sokal, R. R., and F. J. Rohlf. 1981. In Biometry. W. H. Freeman \& Co. Publishers, New York. 1-859.

27. Thakur, M. L., M. J. Welch, J. H. Joist, and R. E. Coleman. 1976. Indium-111 labeled platelets: studies on preparation and evaluation of in vitro and in vivo functions. Thromb. Res. 9:345-357.

28. Heaton, W. A., H. H. Davis, and M. J. Welch. 1979. Indium111: a new radionuclide label for studying human platelet kinetics. Brit. J. Haematol. 42:613-622.

29. Murphy, E. A., and M. E. Francis. 1971. The estimation of blood platelet survival II. The multiple hit model. Thromb. Diath. Haemorrh. 25:53-80.

30. Harker, L. A. 1970. Thrombokinetics in idiopathic thrombocytopenic purpura. Brit. J. Haematol. 19:95-104.

31. Dixon, R. H., and W. F. Rosse. 1977. Mechanism of complement mediated activation of human blood platelets in vitro. Comparison of normal and paroxysmal nocturnal hemoglobinuria platelets. J. Clin. Invest. 59:360-368.

32. Kenney, D. M., and A. E. Davis III. 1981. Association of alternative complement pathway components with human blood platelets: secretion and localization of factor $\mathrm{D}$ and $\beta 1 \mathrm{H}$ globulin. Clin. Immunol. Immunopathol. 21:351-363.

33. Schmaier, A. H., P. M. Smith, and R. W. Colman. 1985. Platelet $\mathrm{C1}$ inhibitor. A secreted alpha-granule protein. J. Clin. Invest. 75:242250.

34. Zimmerman, T. S., and W. P. Kolb. 1976. Human platelet-initiated formation and uptake of the C5-9 complex of human complement. J. Clin. Invest. 57:203-211.

35. Polley, M. J., and R. Nachman. 1978. The human complement system in thrombin-mediated platelet function. J. Exp. Med. 147:17131726.

36. Polley, M. J., and R. Nachman. 1979. Human complement in thrombin-mediated platelet function: uptake of the C5b-9 complex. $J$. Exp. Med. 150:633-645.

37. Wiedmer, T., and P. J. Sims. 1986. Repolarization of the membrane potential of blood platelets after complement damage: evidence for $\mathrm{C} \mathrm{Ca}^{++}$-dependent exocytotic elimination of $\mathrm{C} 5 \mathrm{~b}-9$ pores. Blood. 68 : $556-561$. 